\title{
The ageing trend and related socio-economic issues in Vietnam
}

\author{
Nguyen Viet Cuong ${ }^{* 1}$ \\ ${ }^{1}$ International School, Vietnam National University; Thang Long Institute of \\ Mathematics and Applied Sciences (TIMAS), Thang Long University, Vietnam
}

Vietnam is among the most rapidly ageing countries in the world. Its ageing index of increased during the past 35 years. In 2019, the ageing index was $49 \%$ for the population aged 60 years and older and $33 \%$ for the population aged 65 and older. At the same time, the proportion of older people living alone has been increasing. The main objective of this study is to examine the problem of older people living alone in Vietnam using the logit regression and data from the 2014 Intercensal Population and Housing Survey. In 2014 the proportion of people living alone was $3.2 \%$ among people aged 60 years and older but was $16.4 \%$ among seniors aged 80 years and older. The regression analysis shows that women were more likely to live alone than men, and the probability of living alone was higher among older people with a lower assets level than those with a higher assets level.

Key Words: elderly, ageing trending, living alone, logistic regression, Vietnam.

Article Info: Received: October 1, 2019; Revised: November 17, 2020; Accepted: January 15, 2021; Online: May 31, 2021.

\section{Introduction}

Along with economic development, human health and longevity improved significantly. Increased life expectancy and declining birth rates have increased

* Correspondence address

Address: International School, Vietnam National University, 144 Xuan Thuy street, Cau Giay district, Hanoi, Vietnam.

Phone: + (84)904159258 | Email:cuongnv@isvnu.vn

(C)2021 Human Geographies; The authors

(C) $(0)$ This work is licensed under a

Creative Commons Attribution 4.0 International License. DOI:10.5719/hgeo.2021.151.2 
the trend of population ageing in the world. In 2018, for the first time in history, the number of people aged 65 and over was higher than the number of children younger than 5. A higher share of the elderly population means a lower share of labour participation and lower productivity. Population ageing can reduce economic growth (Park \& Shin, 2012; Otsu \& Shibayama, 2016). The socialeconomic effects of population ageing have been discussed in many studies (Restrepo \& Rozental, 1994; Lee, 2014; Yenilmez, 2015; Otsu \& Shibayama, 2016). One of the results of population ageing is the increase in older people living alone (Rolls et al., 2011; Chen et al., 2014). Living alone is regarded as a risk factor for older people (Lee \& Kim, 2014). Several studies (Mui, 1998; Chou \& Chi, 2000; Gee, 2000; Lê, 2005; Shin \& Sok, 2012; Zebhauser et al., 2015) find that older people living alone tend to have lower health status and life satisfaction than those living with their family. Kharicha et al. (2007) prove a wide range of negative outcomes associated with living alone. More specifically, older people living alone were more likely to report poor health, more difficulties in essential activities of daily living, worse memory and mood swings, lower physical activity, more deficient diet, hazardous alcohol use, and risks of household accidents. Thus, it is vital to understand factors associated with the probability of living alone among older people in order to design policies to target and support them.

In this study, the author examined the ageing trend and the proportion of older people living alone in Vietnam and subsequently examined characteristics of older people associated with the probability of living alone using logistic regression. Vietnam has achieved remarkable economic growth since the implementation of economic reforms starting with 1986. Living standards and the health status of people have improved. Reduced mortality and increased life expectancy have caused the age-sex structure of the population to change remarkably. The proportion of middle-aged and older adults has tended to increase. In 2019, people aged 60 and over in Vietnam accounted for $12.5 \%$ of the total population. According to a World Bank (2018) projection, the share of people older than 65 will account for $20 \%$ of the total population by 2035 . The ageing trend results in challenges in health care and supports for older people, especially those living alone.

Population ageing causes problems for not only health care systems but also the economic growth of a country. Age is one of the most important factors affecting human health, the economy, and human society in general. According to the life-cycle theory, people tend to have high incomes during their young adult and middle ages and lower incomes when they become old and retire (Deaton, 1986; 2005). Income and expenditures for most people depend to a large degree on their age. From the macroeconomic perspective, the age structure of a country's population is a key factor related to economic growth (Bucher, 2012). Different populations have different age structures. Findings about the population's age structure are essential for policymakers, especially for Vietnam, a country in transition in terms of population and economic structure.

Vietnam is a dynamic country with a significant migration flow. Adults are more likely to migrate from rural to urban areas (Dang et al., 2003; Nguyen \& 
Pham, 2016). Although migration of adults can bring higher income for households at their destination, it can cause burdens to the remaining household members, including children and the elderly (Nguyen, 2016; Nguyen \& Vu, 2016). The issue of older people living alone has been studied in many studies which focused on the health and psychological risks of living alone, and there is broad consensus on the adverse effects of living alone (Mui, 1998; Chou \& Chi, 2000; Gee, 2000; Lê, 2005; Shin \& Sok, 2012; Zebhauser et al., 2015). Studies (Gaymu et al., 2016; Reher \& Requena, 2018; Requena et al., 2019) find that women and highly-educated people are more likely to live alone than men and low-educated people. Studies on ageing in Vietnam (Giang \& Pfau, 2007; Long, 2010) examine characteristics of older people and social protections provided for them. Recently, Tran et al. (2018) examine the effect of inequality on life satisfaction of older people and find that higher inequality within communities reduces life satisfaction of older people. To our knowledge, there have been no studies on older people living alone in Vietnam. Thus this study is the first attempt to examine elderly people living alone and analyse characteristics of older people living alone using the Intercensal Population and Housing Survey (IPS, 2014).

This paper is structured into four sections. The second section introduces the data set and method used in this study. The third section presents and discusses the empirical results. The finally fourth section concludes.

\section{Methodology}

In 2014, Vietnam's General Statistics Office (GSO) conducted the Intercensal Population and Housing Survey (IPS). It was a survey with a sample size of $5 \%$ of the total households in Vietnam (1,121,850 households). The main advantage of this data set is the extensive coverage of the population, which allows us to examine the sample of older people, especially those aged above 80. Other sample household surveys which are available in Vietnam, such as Vietnam Household Living Standard Surveys, are not representative for this age group.

The objective of the 2014 IPS was to provide estimates of the size, structure and distribution of the population, as well as economic and social features at a provincial and district level. The information and data collected can be used to analyze changes in the population over time for the whole country, regions, and provinces and to provide evidence for policymaking. Information from this analysis comprises an important input to the design and implementation of development programs and social and economic strategies and policies for various sectors for the period 2015-2020. The data set contains information on individuals' demographic characteristics and education, household conditions, household asset, and appliances. A logistic regression model, which is applied to binary variables (Green, 2011), was used to examine factors associated with the likelihood of living alone among older people. 
The model is expressed as follows:

$$
P\left(y_{i, j}=1 \mid X\right)=\mathrm{F}\left(\beta_{0}+\operatorname{INDIVIDU} A L_{i, j} \beta_{1}+\text { HOUSEHOLD }{ }_{j} \beta_{2}\right)
$$

where $y_{i, j}$ is a dummy variable indicating whether individual $i$ in household $j$ is living alone. INDIVIDUAL $L_{i, j}$ is the vector of individual characteristics such as age and sex, and HOUSEHOLD $D_{j}$ represents household variables such as geographic location and asset level. The logistic function is as follows:

$$
P\left(y_{i, j}=1 \mid X\right)=\mathrm{F}(\mathrm{X} \beta)=\frac{\mathrm{e}^{X \beta}}{1+\mathrm{e}^{X \beta}}
$$

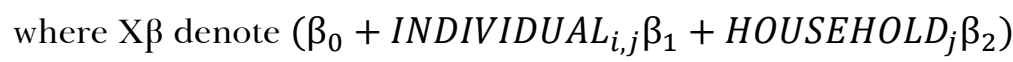

Since the logistic function is non-linear, it is difficult to use the coefficient of explanatory variables for interpretation. The author computed the marginal effect of explanatory variables for interpretation as follows:

$$
M F X=\frac{\partial P\left(y_{i, j}=1 \mid X\right)}{\partial X}=\frac{\partial d F(X \beta)}{\partial X} \beta=\frac{\mathrm{e}^{X \beta}}{1+\mathrm{e}^{X \beta}}\left(1-\frac{\mathrm{e}^{X \beta}}{1+\mathrm{e}^{X \beta}}\right) \beta
$$

Marginal effects change across the values of $X$. Thus, the marginal effect at the mean of $\mathrm{X}$ was computed as:

$$
\widehat{M F X}=\frac{\mathrm{e}^{\bar{X} \widehat{\beta}}}{1+\mathrm{e}^{\bar{X} \widehat{\beta}}}\left(1-\frac{\mathrm{e}^{\bar{X} \widehat{\beta}}}{1+\mathrm{e}^{\bar{X} \widehat{\beta}}}\right) \hat{\beta}
$$

where $\bar{X}$ is the mean of $\mathrm{X}$, and $\hat{\beta}$ is the estimates of $\beta$ in the model. The marginal effect is explained as follows: if $X$ changes by $\Delta \mathrm{X}$, the probability of the dependent variable equal to one will change, on average, by $\widehat{M F X} \Delta X$. This study reports the marginal effects from the logit regression.

According to Glewwe (1991), important explanatory variables in a wellbeing equation include demographic characteristics, assets, and geographic variables. The literature related to older people living alone shows that age, sex, marital status, health, income, education and number of children play a decisive role (Legare \& Martel, 2003; Gaymu et al. 2006; Requen et al. 2019). The factors influencing the decision to live alone can also be classified into demographics, education and economic variables (Reher \& Requena, 2018). In this study, based on data availability, the demographic variables include gender, age, religion, migration and ethnicity of individuals. In the survey, there is a question of whether individuals follow at least one religion, to which $7 \%$ of older people answered affirmatively. Education is measured based on the highest education level and also includes without primary studies, primary, low-secondary, uppersecondary and post-secondary education. Geographic variables consist of urban and regional dummies. In the 2014 IPS, there are no data on income, consumption expenditure, and lands to measure household welfare or assets. To measure the asset levels of households, the author used the principal components approach of Filmer \& Pritchett (2001) to construct an asset index for households. An aggregate asset index is constructed as the first principal component of a 
vector of assets of households, including durables goods, housing characteristics, and access to utilities. Rankings of various welfare measures such as education, health care, income and consumption are very similar to the ranking of asset indices (Filmer \& Scott, 2008; Kolenikov et al., 2009).

In this study, variables that are used to construct the asset index include living area, permanent roof, floor and wall of the house, access to drinking water, improved latrine, fuel, television, telephone, fridge, computer, internet, airconditioning, gas cooker, stove, washing machine, motorbike, car. The principal component approach defines an asset index in terms of the first principal component of the variables used. The asset index, denoted by $A_{j}$, for household $j$ is computed as follows:

$$
A_{j}=\sum_{p} a_{p}\left(\frac{x_{p j}-\bar{x}_{p}}{s_{p}}\right)
$$

where $x_{p}$ denotes the asset $p$, and $\bar{x}$ denote a mean of households in the sample. $s$ is a standard deviation of asset $x_{p}$, and the $p$-domainal vector of weight $a$ is chosen to maximize the sample variance of $A$, subject to $\sum_{p} a_{p}^{2}=1$. The weight $a$ is also called the vector of scores of asset variables, which can be estimated using principal component analysis.

The asset index is standardized to have zero mean and standard deviation of one. Using this asset index, the author classified households by quintiles from the group with the lowest asset index to the group with the highest asset index.

It should be noted that a key assumption of a regression model is that explanatory variables are not correlated with unobserved variables. This is a strong assumption, and therefore interpretation of the results from the regression should be cautious when talking about causal effects. The regression coefficient of an explanatory variable can be interpreted as a correlation between the explanatory variable and the outcome variable after controlling for other explanatory variables in the model instead of a causal effect.

\section{Results and discussion}

\section{The ageing of Vietnam's population over time}

The ageing index often measures ageing. The ageing index shows how many people aged 60 (or 65) years and older are for every 100 children aged 0-14.

Table 1 shows that the ageing index of Vietnam's population has increased in the past 35 years. In 1979, for every 100 children under 15 years, there were only 16.6 people aged 60 years and older. However, after 20 years (1999), the index increased by 1.5 times and continued increasing to reach 43.3 people aged 60 years and older for every 100 children under 15 years in 2014, nearly 3 times higher than in 1979. 
Table 1. Aging index, Vietnam, 1979-2019

\begin{tabular}{ccc}
\hline Year & Aging index 60+ & Aging index 65+ \\
\hline 1979 & 16.6 & 11.3 \\
1989 & 18.2 & 12.0 \\
1999 & 24.3 & 17.5 \\
2009 & 35.5 & 26.1 \\
2014 & 43.3 & 30.3 \\
2019 & 48.8 & 33.2 \\
\hline
\end{tabular}

Source: author's analysis using data from General Statistics Office of Vietnam

The increase in the ageing index reflects an increase in the health and life expectancy of the Vietnamese people. However, it also poses challenges for ensuring pensions and health care for the elderly.

Compared to 10 ASEAN countries, the ageing index of Vietnam (calculated for the population aged 65 years and above) is just below Singapore and Thailand (World Bank, 2016). The ageing index of Vietnam is much higher than countries such as Laos, Cambodia and the Philippines.

Figure 1 shows the differences in the ageing index of the population between urban and rural areas and among socio-economic regions. The difference in the ageing index between urban and rural areas in Vietnam is not significant. For the index calculated based on the population aged 60 and older, the ageing index for urban areas is higher than for rural areas by 2.7 percentage points $(46.4 \%$ versus 43.7\%). Among the six socio-economic regions, the Red River Delta had the highest ageing index. In the Red River Delta, for every 100 children under 15 years old, there were 56.8 people aged 60 and older, while in the Central Highlands, for every 100 children under 15 there were only 23.6 people aged 60 and older.

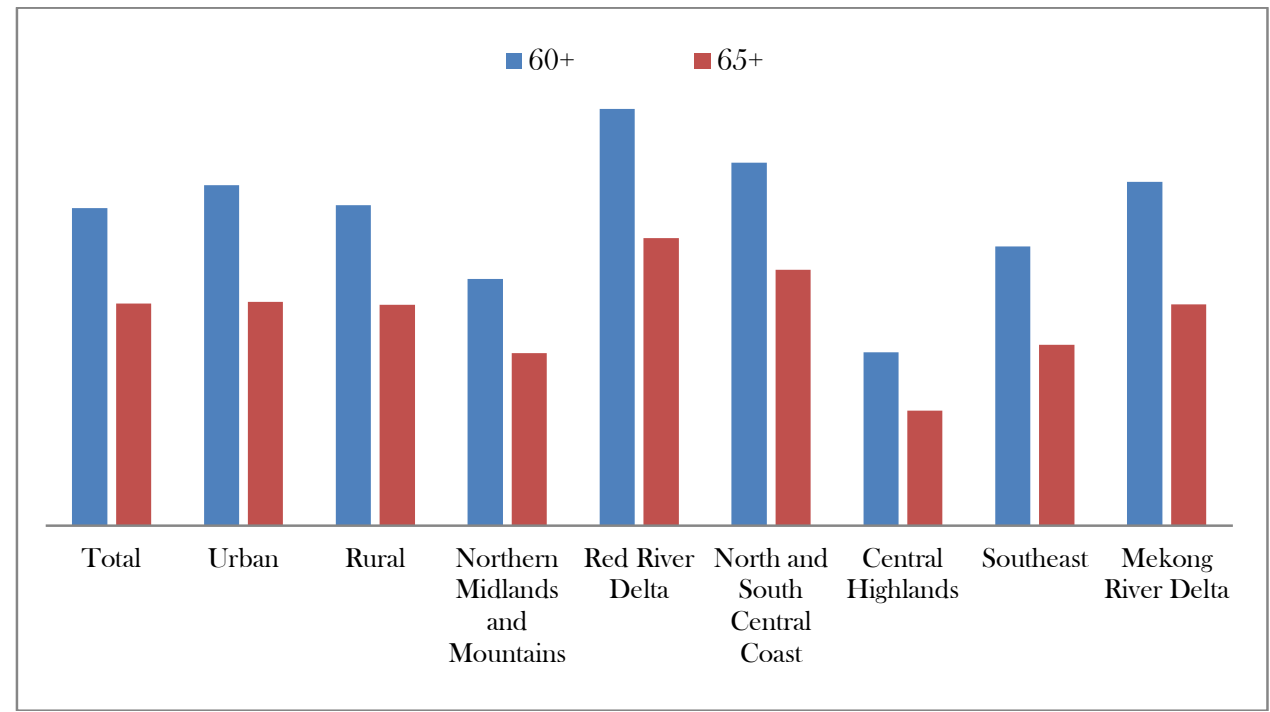

Figure 1. Ageing indices by urban and rural areas and socio-economic regions, 2014 


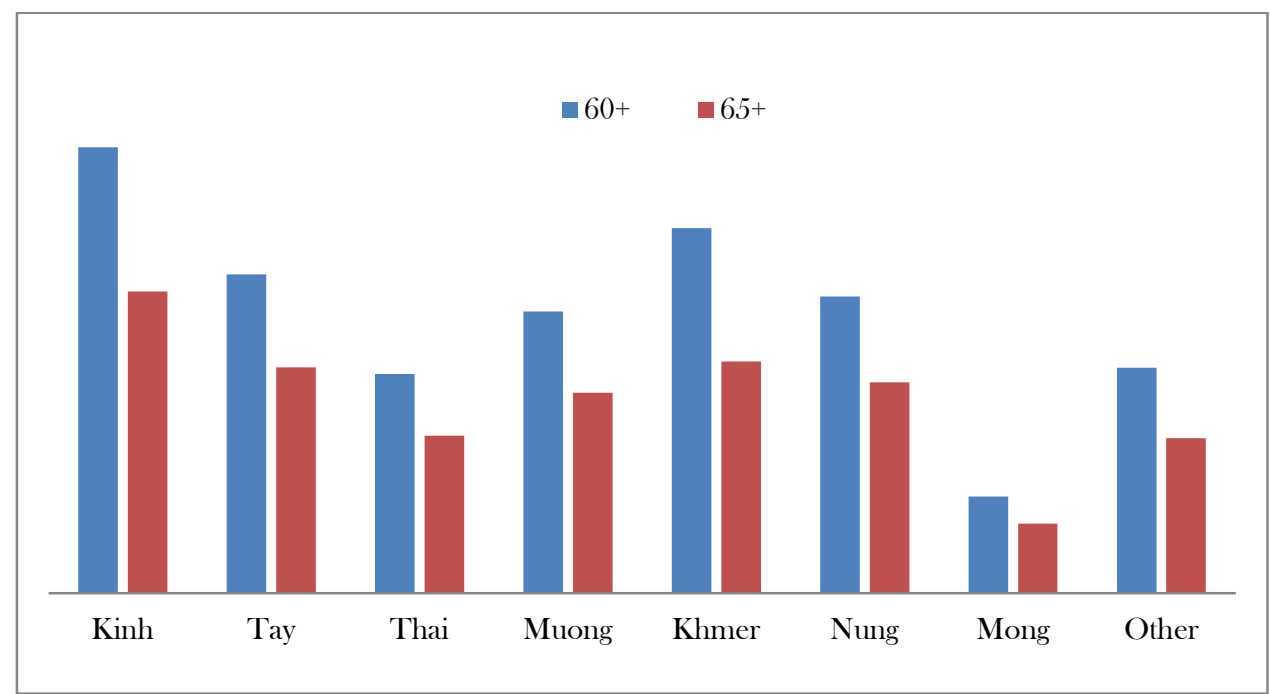

Figure 2. Ageing index by ethnic groups with populations of more than 1 million, 2014

Among the eight ethnic groups with more than one million, the Kinh had the highest ageing index, followed by ethnic Khmer (Figure 2). While the ageing index calculated for the population aged 60 years and older of the Kinh was $47.8 \%$, it was only $10.3 \%$ for the Mong. The difference between ethnic Kinh and Mong is 4.6 times, equivalent to 37.5 percentage points. The main reasons for low ageing indexes in ethnic minority groups are low life expectancy and high fertility rates.

\section{Elderly people living alone and determinants of living alone}

The ageing problem poses many challenges to ensuring the health and welfare of the elderly. A related problem is the increasing number of single elderly people in Vietnam. This problem may be due to the migration of young people and a change in the culture whereby married children no longer live with their parents. The proportion of elderly people who live alone can be estimated using data from the 2014 IPS. Figure 3 shows that in 2014 the proportion of elderly people living alone was 3.2\% among people aged 60 years and older, but was $16.4 \%$ among seniors aged 80 years and older. Elderly women are more likely to live alone than elderly men. This may be due to women's higher life expectancy and a higher rate of widowed women. The rate of re-marriage among women is also lower than among men.

Rural areas had a higher percentage of elderly people living alone than urban areas, primarily due to the rural-urban migration of young people. Figure 3 also provides estimates of the proportion of elderly people who live alone by asset levels. There is a strong positive correlation between the proportion of living alone and asset levels. Approximately $32.4 \%$ of the elderly aged 80 years or older in the group with the lowest asset level were living alone. The proportion in the highest asset level group was just $3.1 \%$. 


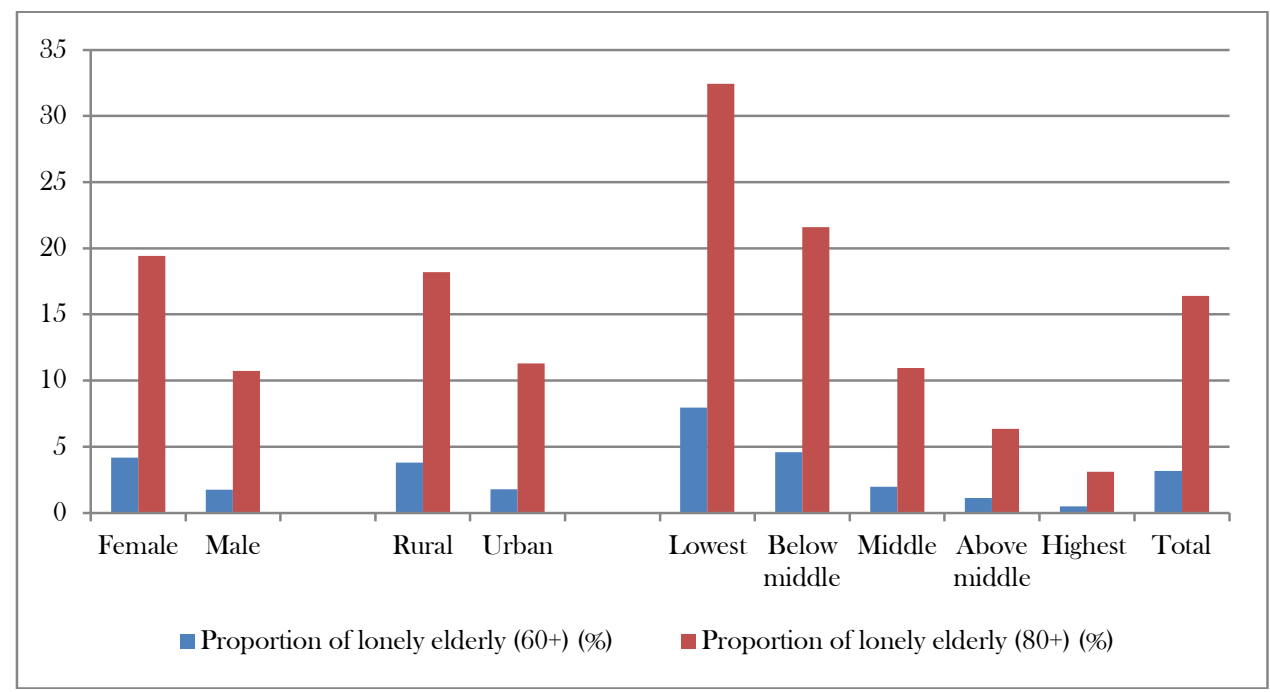

Figure 3. Proportion of elderly people living alone by living conditions, 2014

There is a large difference in the proportion of lonely elderly people between rural and urban areas, with a large proportion in rural areas with low assets levels living alone. This suggests that policies supporting single elderly people should be focused on poor areas and poor groups of elderly.

Regression analysis was used to understand the factors affecting the welfare of individuals. It provides an understanding of the effect of one explanatory variable on a dependent variable after controlling for other explanatory variables. The dependent variable is a dummy variable indicating individuals living alone.

Since the logistic function is non-linear, the coefficient of explanatory variables in the logistic function does not have a clear economic meaning. The marginal effect of explanatory variables was computed to interpret the meaning of the coefficient. Table 2 shows the association between several explanatory variables and the probability of elderly people living alone. The explanatory variables include demographic variables, ethnicity, education, asset index and geography. The signs of explanatory variables in the sample of people aged above 60 and in the sample of people aged above 80 are very similar. However, the magnitude of the explanatory variables in regressions using the sample of people aged above 60 is much lower since the probability of living alone in this sample is much smaller. For interpretation, the regression results from the sample of people aged above 80 were used.

The results show that women have a higher probability of living alone than men. The life expectancy at birth of men and women was 79 and 71 in 2015, respectively (World Bank, 2016). Moreover, women tend to marry older men. Data show that the average age gap between husbands and wives is 2.8. In most societies, women are also found to be more likely to experience the death of a partner and so be living alone (Corden et al., 2008; Requena et al., 2019). The difference in the probability of living alone between men and women is small for people aged above 60 , while it is much larger for people above 80 years old. 
Table 2. Logistic regression of elderly people living alone, 2014

\begin{tabular}{|c|c|c|c|c|}
\hline \multirow[b]{2}{*}{ Explanatory variables } & \multicolumn{2}{|c|}{$\begin{array}{l}\text { Dependent variable is } \\
\text { 'Living alone' } \\
\text { (sample age } 60+\text { ) }\end{array}$} & \multicolumn{2}{|c|}{$\begin{array}{l}\text { Dependent variable is } \\
\text { 'Living alone' } \\
\text { (sample age } 80+\text { ) }\end{array}$} \\
\hline & $\begin{array}{c}\text { Marginal } \\
\text { effect }\end{array}$ & $\begin{array}{c}\text { Standard } \\
\text { error }\end{array}$ & $\begin{array}{c}\text { Marginal } \\
\text { effect }\end{array}$ & $\begin{array}{c}\text { Standard } \\
\text { error }\end{array}$ \\
\hline Male $($ male $=1$, female $=0)$ & $-0.00001 * * *$ & 0.00000 & $-0.07238 * * *$ & 0.00356 \\
\hline Age & $0.00007 * * *$ & 0.00001 & $0.04454 * * *$ & 0.01245 \\
\hline Age squared & $-0.00000^{* * *}$ & 0.00000 & $-0.00025 * * *$ & 0.00007 \\
\hline Religion $($ yes $=1$, no=0) & $0.00000 * *$ & 0.00000 & $0.01362 * *$ & 0.00549 \\
\hline $\begin{array}{l}\text { Migrated in the past } 5 \text { years } \\
(\text { yes }=1, \text { no }=0)\end{array}$ & -0.00000 & 0.00000 & -0.02406 & 0.02038 \\
\hline Other ethnic minorities & Reference & & & \\
\hline Kinh & $0.00002 * * *$ & 0.00000 & $0.09368 * * *$ & 0.00602 \\
\hline Tày & -0.00000 & 0.00000 & -0.02488 & 0.02121 \\
\hline Thái & $-0.00001 * * *$ & 0.00000 & $-0.06452 * * *$ & 0.01404 \\
\hline Mường & -0.00001 & 0.00000 & -0.03271 & 0.02513 \\
\hline Khmer & $0.00002 *$ & 0.00001 & $0.08913 * *$ & 0.04455 \\
\hline Nùng & 0.00000 & 0.00001 & 0.01570 & 0.03531 \\
\hline Mông & $-0.00001 * * *$ & 0.00000 & $-0.08152 * * *$ & 0.01113 \\
\hline $\begin{array}{l}\text { Less than primary education } \\
\text { degree }\end{array}$ & Reference & & & \\
\hline Have primary degree & $0.00000^{* *}$ & 0.00000 & $0.01400 * * *$ & 0.00509 \\
\hline Have lower-secondary degree & $0.00001 * *$ & 0.00000 & $0.02896 * * *$ & 0.01112 \\
\hline Have upper-secondary degree & $0.00002 * * *$ & 0.00001 & $0.08688 * * *$ & 0.02495 \\
\hline Have college, university & $0.00001 *$ & 0.00001 & $0.07010^{*}$ & 0.03641 \\
\hline Lowest asset quintile & Reference & & & \\
\hline Near lowest asset quintile & $-0.00001 * * *$ & 0.00000 & $-0.07355^{* * *}$ & 0.00347 \\
\hline Middle asset quintile & $-0.00002 * * *$ & 0.00000 & $-0.11390 * * *$ & 0.00338 \\
\hline Near highest asset quintile & $-0.00003 * * *$ & 0.00001 & $-0.14269 * * *$ & 0.00365 \\
\hline High asset quintile & $-0.00004 * * *$ & 0.00001 & $-0.17827 * * *$ & 0.00398 \\
\hline Urban $($ urban $=1$, rural $=0)$ & $0.00001 * * *$ & 0.00000 & $0.05481 * * *$ & 0.00683 \\
\hline $\begin{array}{l}\text { Northern Midlands and } \\
\text { Mountains }\end{array}$ & Reference & & & \\
\hline Red River Delta & $0.00003 * * *$ & 0.00001 & $0.13146^{* * *}$ & 0.01147 \\
\hline $\begin{array}{l}\text { North and South Central } \\
\text { Coast }\end{array}$ & $0.00001 * * *$ & 0.00000 & $0.04060 * * *$ & 0.00852 \\
\hline Central Highlands & 0.00000 & 0.00000 & 0.01482 & 0.01377 \\
\hline Southeast & $0.00001 * * *$ & 0.00000 & $0.05528 * * *$ & 0.01495 \\
\hline Mekong River Delta & $-0.00000 * * *$ & 0.00000 & $-0.02141 * * *$ & 0.00733 \\
\hline Observations & 140,887 & & 27,438 & \\
\hline R-squared & 0.465 & & 0.198 & \\
\hline
\end{tabular}

Note: ${ }^{* \star}$ statistically significant at $1 \%$; $* \star$ at $5 \%$; and ${ }^{*}$ at $1 \%$.

Source: author's analysis of data from the 2014 IPS

Compared with women, the probability of living alone among men is 0.072 lower. This finding is also similar to other countries such as China (Chou et al., 2000) or the USA (Corden et al., 2008). 
The positive sign of age and the negative sign of age squared in the regression result indicate an inverted- $U$ shape relation between age and the probability of living alone. Older people are more likely to living alone, but after a certain age, this will decrease. As people grow older, they are more likely to face serious health problems and are decreasingly able to care for themselves (Reher \& Requena, 2018). Living alone can push them into higher health risks. For the sample of people above 80 , the peak of the inverted- $U$ shape is 89 (it is equal to 0.04454. $(2 * 0.00025))$. This means that the probability of living alone tends to decrease after the age of 89 .

Living alone is also influenced by culture, represented by religion (Pew Research Center, 2019). Table 2 shows that religious people have a higher rate of living alone than non-religious people, especially among those aged 80 years and older. In particular, after controlling for variables in the model, the proportion of single elderly religious people is higher than the proportion of non-religious ones by about 1.4 percentage points.

Kinh people have a higher proportion of elderly people living alone than ethnic minority people. This is primarily because the migration rate of Kinh is higher than among ethnic minorities. Also, because of migration, rural areas tend to have a higher rate of single older people than urban areas; young people migrate to urban areas and leave older people behind in rural areas.

Older people in wealthier asset quintiles are less likely to live alone. This finding is consistent with findings from several studies such as Mui (1998) and Chou \& Chi (2000). Living alone has a higher financial risk. Thus the provision of financial supports for older people without family is very important.

Older people with higher education levels tend to live alone than those with lower education. This finding is consistent with several studies (Gaymu et al., 2016; Reher \& Requena, 2018; Requena et al., 2019). Highly educated people may be more likely to live alone due to a higher probability of divorce, to lower fertility, or simply to preference (Reher \& Requena, 2018; Requena et al., 2019). Table 2 shows that people with upper-secondary education and those with postsecondary education in the sample aged from 80 have the probability of living alone 0.086 and 0.070 higher than people with less than primary education (the reference group), respectively.

\section{Conclusions}

The ageing index of Vietnam's population increased during the past years. In 2019 , the ageing index was $49 \%$ for the population from 60 years and older and $33 \%$ for the population aged 65 and older. Among the 10 ASEAN countries, the ageing index of Vietnam was just lower than Singapore and Thailand.

There is a growing trend of older people to live alone in Vietnam. Rural areas had a higher ratio of single than in urban areas. The Red River Delta and the central regions had a higher ratio of single older people than other regions, while the Southeast and Mekong River Delta had the lowest ratio of single elderly 
people. Women were more likely to live alone than men. Older and poorer people are more likely to live alone than younger and richer people.

Population projections indicate that the proportion of elderly people in Vietnam will grow rapidly in the coming years. The country will face the challenge of population ageing because many of these people are economically dependent on others and have chronic diseases. Social insurance policies and health insurance programs should be developed and modified to adapt to an ageing population. The government should have strategies and policies to ensure health care for a larger elderly population in the future. Raising the retirement age and better managing pension funds can be effective measures to ensure the affordability of insurance funds and social security for the elderly.

The issue of single elderly people also needs attention. Rural-urban migration of young people had led to an increasing number of elderly people living alone in rural areas. Older people have high risks of health and financial problems. For the case of Vietnam, older people living alone are found to have lower living conditions and assets levels than others. This suggests that social pensions and allowances for older people living alone are crucial to improve their quality of life.

\section{Acknowledgements}

This study is a result of the research team with the title 'Mathematical Models in Economics and Application in solving some problems of Economics and the Social Sciences' led by Dr. Phung Duy Quang, Foreign Trade University, Vietnam.

\section{References}

Bucher, S. (2012), "Aspects of the phenomenon of demographic population aging in Czechia and Slovakia: Time and regional dimensions", Human Geographies Journal of Studies E Research in Human Geography, vol. no. 1, p. 25-33.

Chen, Y., Hicks, A. and While, A.E. (2014), "Quality of life and related factors: a questionnaire survey of older people living alone in Mainland China", Quality of Life Research, vol. 23, no. 5, p. 1593-1602.

Chou, K.L. and Chi, I. (2000), "Comparison between elderly Chinese living alone and those living with others", Journal of Gerontological Social Work, vol. 33, no. 4, p. 51-66.

Corden, A., Hirst, M. and Nice, K. (2008), "Financial implications of death of a partner", Social Policy Research Unit, University of York.

Dang, N.A., Tackle, C. and Hoang, X.T. (2003), "Migration in Viet Nam: A review of information on current trends and patterns, and their policy implications", Paper presented at the Regional Conference on Migration, Development and Pro-Poor Policy Choices in Asia, 22-24 June 2003, Dhaka, Bangladesh. 
Deaton, A. (1986), "Life-cycle models of consumption: Is the evidence consistent with the theory?", NBER Working Papers 1910, National Bureau of Economic Research.

Deaton, A. (2005), "Franco modigliani and the life cycle theory of consumption", Research Program in Development Studies and Center for Health and Wellbeing, Princeton University.

Filmer, D. and Pritchett, L.H. (2001), "Estimating wealth effects without expenditure data-or tears: an application to educational enrollments in states of India", Demography, vol. 38, no. 1, p. 115-132.

Filmer, D. and Scott, K. (2008), Assessing Asset Indices, The World Bank.

Gaymu, J., Delbès, C., Springer, S., Binet, A., Désesquelles, A., Kalogirou, S. and Ziegler, U. (2006), "Determinants of the living arrangements of older people in Europe", European Journal of Population, vol. 22, no. 3, p. 241-262.

Gee, E.M. (2000), "Living arrangements and quality of life among Chinese Canadian elders", Social Indicators Research, vol. 51, p. 309-329.

Giang, T.L. and Pfau, W.D. (2007), "The elderly population in Vietnam during economic transformation: an overview", MPRA Paper No. 24948, Munich Personal RePEc Archive.

Glewwe, P. (1991), "Investigating the determinants of household welfare in Cote d'Ivoire", Journal of Development Economics, vol. 35, no. 2, p. 307-337.

Green, H.W. (2011), Econometric Analysis, Prentice Hall Publisher.

Kharicha, K., Iliffe, S., Harari, D., Swift, C., Gillmann, G. and Stuck, A.E. (2007), "Health risk appraisal in older people 1: are older people living alone an 'atrisk' group?", British Journal of General Practice, vol. 57, no. 537, p. 271-276.

Kolenikov, S. and Angeles, G. (2009), "Socioeconomic status measurement with discrete proxy variables: Is principal component analysis a reliable answer?", The Review of Income and Wealth, vol. 55, p. 128-165.

Lee, J.J. (2005), "An exploratory study on the quality of life of older Chinese people living alone in Hong Kong" in D.T.L. Shek, Y.K. Chan and S.N Lee (eds.) Quality-of-Life Research in Chinese, Western and Global Contexts, p. 335-361, Springer, Dordrecht.

Lee, M. and Kim, K. (2014), "Prevalence and risk factors for self-neglect among older adults living alone in South Korea, The International Journal of Aging and Human Development, vol. 78, no. 2, p. 115-131.

Lee, R.D. (2014), "Macroeconomic consequences of population aging in the United States: Overview of a national academy report", American Economic Review, vol. 104, no. 5, p. 234-239.

Legare, J. and Martel, L. (2003), "Living arrangements of older persons in the early ninety's: an international comparison", Genus, vol. 59, no. 1, p. 85-103.

Long, G.T. (2010), "Social protection in Vietnam: Current state and challenges" in M.G. Asher, S. Oum and F. Parulian (eds.) Social Protection in East Asia Current State and Challenges, ERIA Research Project Report 2009-9, Jakarta: ERIA, p. 292-315.

Mui, A.C. (1998), "Living alone and depression among older Chinese immigrants", Journal of Gerontological Social Work, vol. 30, p. 147-166. 
Nguyen, C. (2016), "Does parental migration really benefit left-behind children? Comparative evidence from Ethiopia, India, Peru and Vietnam", Social Science E Medicine, vol. 153(C), p. 230-239.

Nguyen, C. and Pham, T. (2016), "Are migrants in large cities underpaid? Evidence from Vietnam", IZA Journal of Migration, vol. 5, no. 1, p. 1-23.

Nguyen, C. and Vu, L. (2016), "Should Parents Work Away from or Close to Home? The Effect of Parental Absence on Children's Time Use in Vietnam", Journal of Human Development and Capabilities, vol. 17, no. 1, p. 110-124.

Otsu, K. and Shibayama, K. (2016), "Population aging and potential growth in Asia", Asian Development Review, vol. 33, no. 2, p. 56-73.

Park, D. and Shin, K. (2012), "Impact of population aging on Asia's future growth", ADB Economics Working Paper Series, no. 281, Asian Development Bank, Manila, Philippines.

Pew Research Center (2019), Religion and living arrangements around the world, Pew Research Center, Washington, D.C. USA, 12 march 2020, shorturl.at/lP689.

Reher, D. and Requena, M. (2018), "Living alone in later life: A global perspective", Population and Development Review, vol. 44, no. 3, p. 427-454.

Requena, M., Reher, D., Padyab, M. and Sandström, G. (2019), "Women living alone in later life: A multicountry comparative analysis", Population, Space and Place, vol. 25, no.7, p. 22-69.

Restrepo, H.E. and Rozental, M. (1994), "The social impact of aging populations: some major issues", Social Science $\mathcal{E}^{\circ}$ Medicine, vol. 39, no. 9, p. 1323-1338.

Rolls, L., Seymour, J.E., Froggatt, K.A. and Hanratty, B. (2011), "Older people living alone at the end of life in the UK: research and policy challenges", Palliative Medicine, vol. 25, no. 6, p. 650-657.

Shin, S.H. and Sok, S.R. (2012), "A comparison of the factors influencing life satisfaction between Korean older people living with family and living alone", International Nursing Review, vol. 59, no. 2, p. 252-258.

Tran, T.Q., Nguyen, C.V. and Van Vu, H. (2018), "Does economic inequality affect the quality of life of older people in rural Vietnam?", Journal of Happiness Studies, vol. 19, no. 3, p. 781-799.

World Bank (2016), World Development Indication, World Bank, 15 January 2020, https://data.worldbank.org/indicator.

World Bank (2018), World Development Indicators, World Bank, 15 January 2020, https://data.worldbank.org/indicator.

Yenilmez, M.I. (2015), "Economic and social consequences of population aging the dilemmas and opportunities in the twenty-first century", Applied Research in Quality of Life, vol. 10, no. 4, p. 735-752.

Zebhauser, A., Baumert, J., Emeny, R.T., Ronel, J., Peters, A. and Ladwig, K.H. (2015), "What prevents old people living alone from feeling lonely? Findings from the KORA-Age-study", Aging \& mental health, vol. 19, no. 9, p. 773-780. 